\title{
Adaptation to Climate Change in Water Management, Agrobiodiversity and Forestry with Special Reference to Nepal
}

\author{
Ujjwal T. Shrestha ${ }^{1}$
}

\begin{abstract}
Analysis of recent climatic trends reveals a significant sign of warming in recent decades which has been more pronounced at higher altitudes. Climate change scenarios for Nepal show considerable convergence on continued warming, Warming trends have already had significant impacts in the Nepal Himalayas -most significantly in terms of glacier retreat such as increase in size and volume of glacial lakes, making them more prone to glacial lake outburst flooding (GLOF). This contributes to enhanced variability of river flows. The indepth analysis of water resources in Nepal identifies two critical impacts of climate changeGLOFs and variability of river runoff- both of which pose significant impacts not only on hydropower, but also on rural livelihoods and agriculture. The range of practices that can be used to adapt the climate change is diverse, and includes changes in behavior, structural policy based responses, technological or managerial responses.
\end{abstract}

Key Words: Adaptation, Climate change, Forestry, Agrobiodiversity, GLOF

Worldwide, climate change is posing a serious challenge for conservation planning. Most institutions and procedures are strongly orientated towards conserving species and habitats where they currently occur, however climate change means that at least some aspects of habitat are going to move.

A growing body of research indicates that global biodiversity is particularly at risk due to the relatively rapid climate change projected for the twenty-first century (Thomas et al., 2004; Hannah et al., 2005).

Rising temperatures will have serious effects on rainfall, strength and distribution of tropical storms, increase in sea level and glacier melt, thereby causing greater risks to livelihood and increasing damage-related costs. The climate change has serious impacts on the prospect of water and food shortages, coastal inundation, distribution of vector-borne diseases such as malaria and dengue fever, and the rate of extinction of many biological species (up to 30 percent with a $2^{\circ} \mathrm{C}$ rise in temperature).

It has been mentioned that the mid-range of expectations for climate change in Australia is approximately $3^{\circ} \mathrm{C}$ warming by 2050-2100, compared to 1990 baseline (IPCC, 2001; Hughes, 2003). A $3^{\circ} \mathrm{C}$ warming means that for species with a north-south range less than about 300 $\mathrm{km}$, or with an elevation range less than about $300 \mathrm{~m}$, their present-day temperature envelope

\footnotetext{
${ }^{1}$ Central Department of Environmental Science,Tribhuvan University, Kirtipur,Kathmandu, Nepal.ujjwal_ts@hotmail.com
} 
will become completely dissociated from their present-day distribution (Westoby, M. et al., 2006).

Extreme climatic event is a term that encompasses the bulk of natural hazards. Climate change is expected to increase the number and strength of these natural hazards in coming years, leading to an incremental rise in the vulnerability of natural and social systems (IPCC, 2001a). As systems become more vulnerable to natural hazards, there is a greater need to develop responses (that is, adjustments in existing practices, processes or structures) that are able to counter potential future disasters. Such a response is known as adaptation to climate change (IPCC, 2001b; Smit et al., 1999).

The earth's surface temperature is rising, thereby changing the earth's climate. Adaptation is about finding and implementing ways of adjusting to climate change. Adaptation is vital, even if countries reduce their greenhouse gas emissions, because the greenhouse gases already in the atmosphere will continue to cause a rise in temperature. The IPCC report predicts that by 2100 , average global temperatures will rise to at least $1.8^{\circ} \mathrm{C}$ and may get high upto $4^{\circ} \mathrm{C}$, depending on different emission scenarios (UNFCCC).

The climate in Nepal varies from the tropical to the arctic within the $200 \mathrm{~km}$ span from South to North. Much of Nepal falls within the monsoon region with regional climate variations largely being a function of elevation. National mean temperatures hover around $15{ }^{\circ} \mathrm{C}$, and increase from North to South with the exception of mountain valleys. Average rainfall is $1,500 \mathrm{~mm}$, with rainfall increasing from West to East (USCSP 1997 as cited in OECD, 2003). Although annual rainfall is abundant, its distribution is of great concern: flooding is frequent in the monsoon season during the summer, while droughts are not uncommon in certain regions in other parts of the year (OECD, 2003).

Temperature observations in Nepal from 1977-1994 shows a general warming trend (Shrestha et al., 1999). The temperature differences are most pronounced during the dry winter season, and least during the peak monsoon. Significant glacier retreat as well as aerial expansion of several glacial lakes has also been documented in recent decades with an extremely high likelihood that such impacts are linked to rising temperatures. There are no definitive trends in aggregate precipitation, although there is some evidence of more intense precipitation events.

\section{Different Methods of Adaptation}

Adapting to climate change will entail adjustments and changes at every level ranging from community-based to national and eventually to international level. The range of practices that can be used to adapt the climate change is diverse which includes:

- changes in behavior ( e.g. water use or farming practices),

- structural changes ( e.g. the design specification of bridges and roads),

- policy based responses (e.g. integrating risk management and adaptation into development policy),

- technological responses (e.g. increase sea defences, improve forecasting) and

- managerial responses (e.g. improve forest management and biodiversity conservation) 
Any successful adaptation strategy needs to be based on sound scientific assessment. In response to this need, the Nairobi work programme on impacts, vulnerability and adaptation to climate change was launched in 2005 (UNFCCC).

\section{National Adaptation Programmes of Action}

Developing countries are the most vulnerable to impact of climate change since they have fewer resources to adapt. However a number of developing countries have drawn up adaptation plans or are in the process of finalizing them. This includes the National Adaptation Programmes of Action (NAPAs) of least developed countries. The NAPAs allow identification of priority activities that respond to immediate needs and concerns for adaptation to climate change. They build upon existing coping strategies at the grassroots level and promote the use of relevant traditional knowledge and practice (UNFCCC).

Climate change requires a global framework for international cooperation, and adaptive actions which are vital parts of this framework. Furthermore, any action taken to enable adaptation to climate change raises opportunities to promote sustainable development. However, developing countries require resources in order to promote these actions. A successful framework must therefore directly involve assistance for adaptation in developing countries, particularly least developed countries.

\section{Adaptation in Water Management}

A broad range of agricultural water management practices and technologies are available to spread and buffer production risks. Enhancing residual soil moisture through land conservation techniques assists significantly at the margin of dry periods while buffer strips, mulching and zero tillage help to mitigate soil erosion risk in areas where rainfall intensities are high. The inter-annual storage of excess rainfall and the use of resource efficient irrigation remain the only guaranteed means for maintaining cropping intensities. Beyond the direct agricultural interventions, water resource management responses for river basins and aquifers, which are often transboundary, will be forced to become more agile and adaptive (including near realtime management), as variability in river flows and aquifer recharge becomes apparent (FAO, 2007).

\section{Climate Change in the Nepalese Perspective}

Nepal's Country Profile for the World Summit on Sustainable Development (WSSD, 2002) discusses climate change only in the context of mitigation of greenhouse gas emissions and adaptation to climate change is not mentioned. However, the section on sustainable mountain development pays attention to indigenous systems of human adaptation to challenging geographic and climatic circumstances in mountainous areas. Furthermore, many elements of the proposed sustainable development policies (designed for current climatic circumstances) would also be no-regrets measures for adaptation to climate change (OECD, 2003).

Sustainable Development Agenda for Nepal (SDAN) which is the National Strategy for Sustainable Development (NSSD) has not mentioned climate change as a risk in the context 
of sustainable development challenges, except in the case of biodiversity and natural disasters (increasing risk of GLOFs). For mitigating climate risks, including natural hazards such as floods and droughts, concrete disaster mitigation measures including following measures are proposed (OECD, 2003):

- establishment of a national disaster preparedness and management agency,

- creation of village-level early warning systems for floods, landslides or earthquakes, building decentralized and emergency response capacity,

- enforcing design standards for buildings and infrastructure that take into account sitespecific risks,

- investing in better weather and earthquake prediction systems, and,

- specifically for GLOFS, monitoring of the lakes and preparation of siphon materials.

\section{Adaptation Options for GLOF Risks and Stream Flow Variability}

A number of adaptation strategies are in fact available to cope with both GLOF risks as well as changes in stream flow variability. Some of these responses are already in varying stages for implementation within the context of development projects. Although such responses tend to be more clustered on the mapping and (engineering based) reduction of GLOF risks they are not enough to reduce social vulnerability or to cope with enhanced stream flow variability (OECD, 2003).

\section{Siting in non-threatened locations}

This adaptation option reduces vulnerability of GLOF risks by moving proposed hydropower plants to alternative locations. This risk of a GLOF occurring is relevant to the construction of both small-scale hydropower and large-scale. The former because they are often located in close proximity to potential sites. The latter because of the danger of damage, clogging, and much faster rates of siltation than designs can cope with (Ives, 1986 as cited in OECD, 2003).

\section{Smaller hydropower plants}

Hydropower in Nepal is divided into five categories:

Micro - up to $100 \mathrm{KW}$

Small $-101 \mathrm{~kW}$ to $10 \mathrm{MW}$

Medium - $10 \mathrm{MW}$ to $35 \mathrm{MW}$

Large - greater than $35 \mathrm{MW}$

One adaptation response to GLOF risks is to promote the development of smaller plants, would also spread the risk of a catastrophic flooding event and avoid damage to a huge plant with significant sunk costs. Micro-hydropower has the potential to fulfil a large amount of the rural demand for energy. Water wheels (ghatta) have already been used in Nepal for hundreds of years to process agricultural products (OECD, 2003). 


\section{Reduction in GLOF risks}

Another set of adaptation responses to GLOF hazards revolves around the physical reduction in the flooding risks of glacial lakes. Rana et al (2000) list several solutions such as:

- Draining the lake by siphon or pump

- Cutting a drainage channel out the lake for periodical drain

- Flood control measures downstream to mitigate the effects of the flood

- Developing a GLOF early warning system

GLOF mitigation measures however each have their own disadvantages. Pumping is expensive because of the remote location at high altitudes and heavy infrastructure must be flown by helicopter to the site.

\section{Integrated water resource and disaster management}

The above measures are aimed at reducing the direct risks of climate change-induced GLOFs and runoff changes on the hydropower sector. A broader perspective on Nepal's development patterns incorporating migration, watershed management, flood management, and disaster preparedness will also help communities adapt to climate change. One of the most important indicators of vulnerability to climate change and disasters is poverty. This is the unfortunate situation for most Nepalese living in mountainous and hill regions. Only $2 \%$ of the land is suitable for cultivation, and it can support only $8 \%$ of the population (Tianchi and Behrens, 2002 as cited in OECD, 2003).

\section{Energy supply and demand management}

At its core, the various impacts of climate change (GLOFs, stream flow variability; reduced low flow dependability; increased sediment loads from floods and strong precipitation events) affect Nepal's hydroelectric potential. This is particularly significant, given that hydropower contributes over $90 \%$ of Nepal's electricity generation. Among the adaptation options in the energy sector therefore are: alternate sources of energy supply, and better demand side management.

The potential non-hydro energy options for Nepal include: fossil fuels (coal, petroleum, natural gas); biogas and agricultural residues; and solar energy. Agricultural residues, solar and biogas have made promising results in Nepal's energy consumption; however they face constraints with regard to their overall potential. The efficiency of conversion is a major constraint for agricultural residues, while cost is the limiting factor for solar photovoltaics. Biogas has been considerably more successful and has the potential to meet one-third of current energy consumption.

\section{Adaptation in Forestry}

Forest covers 27.9 percent of the total land surface of Nepal, while the world's 57 countries have less than $10 \%$ of their land area in forests. In addition to adapting forests to climate 
change, forests can play significant role in adaptation to climate change by helping human societies to adapt to climate change (FAO, 2007).

Adaptive management of forests will contribute to sustaining the livelihood of over two billion people worldwide. Many existing forests and most newly established stands will experience climatic conditions that deviate from conditions today (FAO, 2007).

The first harbingers of forest climate change impacts are visible as forest decline on former permafrost soils in Canada and Alaska, as decline of cloud forests in the tropics, the global frequency and severity of forest fires, altered timing of seeding and as increased pest and disease outbreaks.

Preliminary analysis indicates that concepts and contingency plans for adapting forests are rarely included in national plans for adaptation. FAO has begun systematically informing forestry administrations in regional organizations and member countries about climate change, the vulnerabilities of their forest sector and possible adaptive options. Projected long-term impacts of climate change on forests, ranging from pronounced increases in productivity in some northern countries to die-back of some tropical forests are available. FAO can offer decision models for managing forests under uncertainty, and management options for intensively managed forests in regeneration, tending, harvesting, protection, conservation and management planning (FAO, 2007).

Unfortunately forests which are managed at low intensity or not at all, particularly the tropical forests, fewer options exist and uncertainty is more pronounced regarding climate change adaptation. Intensifying assessment and monitoring, establishing new tools and indicators to rate vulnerability and targeting research efforts appear most promising to cope with climate change in these forests.

FAO is closely involved with UNFCCC efforts to reduce emissions from deforestation in developing countries. While this might be seen as primarily aimed at mitigating climate change, it has an adaptive component of preserving FAO Work Related to Climate Change Adaptation, species richness, continuity of forest ecosystems and resilience. It is estimated that adverse climate change impacts will contribute to the destruction of forests and thereby promote the emission of greenhouse gases, which in turn will enhance global warming (FAO, 2007).

\section{Adaptation in Agrobiodiversity}

Biodiversity in all its components (e.g. genes, species, and ecosystems) increases resilience to changing environmental conditions and stresses. Genetically-diverse populations and species-rich ecosystems have greater potential to adapt to climate change. Use of indigenous and locally-adapted plants and animals as well as the selection and multiplication of crop varieties and autochthonous races adapted or resistant to adverse conditions can be done for adapting changing environmental conditions.

To strengthen capacity of developing countries to implement plant breeding programmes and develop locally-adapted crops, FAO and other like-minded institutions are planning the Global Initiative on Plant Breeding Capacity Build (GIPB) initiative, to be launched at the governing 
body meeting of the International Treaty on Plant Genetic Resources for Food and Agriculture (Madrid, June 2007).

Work on adapted crops cannot be separated from other management options within agroecosystems. A specific example is rice, which is both impacted by and impacts climate. Climate change is expected to significantly impact the productivity of rice systems and thus the nutrition and livelihood of millions of people. Rice varieties have different abilities to tolerate high temperature, salinity, drought and floods. Rice varieties with salinity tolerance have been used to expedite the recovery of production in areas damaged by the 2004 Asian tsunami. The selection of appropriate rice varieties deserves consideration for adaptation to climate change taking into account more than high yielding potential (FAO, 2007).

Emission of methane from flooded rice soils has been identified as a contributor to global warming. Varietal differences could be used to lessen the methane emission in rice production. Also, intermittent irrigation and/or alternating dry-wet irrigation could reduce methane emission from rice fields, while the transfer and adoption of the Rice Integrated Crop Management (RICM) system, such as the Australian RiceCheck, would increase the efficiency of nitrogen fertilizer in rice production, thus reducing the nitrous oxide (a greenhouse gas) emission. Upland rice cultivation under slash-and-burn shifting cultivation, especially in sub- Saharan Africa has resulted in destruction of forest vegetation. The development of wetland rice in sub-Saharan Africa could reduce deforestation in these areas (FAO, 2007).

\section{Conclusion}

Despite its natural beauty and enormous potential for hydropower and tourism, Nepal is one of the poorest countries in the world, with $82.5 \%$ of the population living below the international poverty line of $\$ 2$ per day (World Bank 2003). A heavy reliance on tourism and agriculture makes Nepal's economy very sensitive to climate variability (World Bank, 2002).

Water resources and hydropower rank significantly higher than any other sector for several reasons. First, a number of impacts on water resources and hydropower are directly related to rising temperatures that have already been observed, and are projected (with high confidence) to increase further over the coming decades. This includes glacier retreat that in turn causes greater variability (and eventual reduction) in streamflow, and glacial lake outburst floods that pose significant risk to hydropower facilities, and also to other infrastructure and human settlements. The significance of water resources to agriculture, and the significance of hydropower to the nations electricity supply (a $92 \%$ share) further justify the high ranking for water resources and hydropower. The impacts of climate change on other sectors tend to be less direct and/or less immediate, and much more speculative - even though the sectors themselves are quite significant. Three sectors that fall in this cluster are agriculture, human health, and ecosystems/biodiversity. Agriculture is very important for the country because a large portion of its output and labor force are devoted to it (OECD, 2003).

Mountains are regarded as barometer of Climate Change. Analysis of maximum temperature data from 49 stations in Nepal for the period of 1971-1994 reveal warming trends after 1977. Warming trends have already had significant impacts in the Nepal Himalayas-most significantly 
in terms of glacier retreat and significant increases in the size and volume of glacial lakes, making them more prone to Glacial Lake Outburst Flooding (GLOF). Continued glacier retreat can also reduce dry season flows fed by glacier melt, while there is moderate confidence across climate models that the monsoon might intensify under climate change. This contributes to enhanced variability of river flows. So studies of climate change are urgently needed to understand the linkage between changing climatic pattern and increasing natural hazards and its environmental consequences. Based on the impacts predicted appropriate strategies should be developed at the national, regional and local level.

\section{References:}

Agrawala, S., Raksakulthai, V., Aalst, M.V., Larsen, P., Smith, J. and Reynolds, J., DEVELOPMENT AND CLIMATE CHANGE IN NEPAL: FOCUS ON WATER RESOURCES AND HYDROPOWER.

FAO 2007, Adaptation to climate change in agriculture, forestry and fisheries: Perspective, framework and priorities.

IPCC (2001b) Climate Change 2001: Impacts, Adaptation and Vulnerability. Contribution of Working Group II to the Third Assessment Report of the Intergovernmental Panel on Climate Change. J.J. et al. McCarthy (eds.). Cambridge University Press, Cambridge.

IPCC (Intergovernmental Panel on Climate Change) (2001a) Climate Change 2001: The Scientific Basis. Contribution of Working Group I to the Third Assessment Report of the Intergovernmental Panel on Climate Change. J.T. Houghton et al. (eds.). Cambridge University Press, Cambridge.

Rana, B., A.B. Shrestha, J.M. Reynolds, R. Aryal, A.P. Pokhrel, and K.P. Budhathoki, 2000. "Hazard assessment of the Tsho Rolpa Glacier Lake and ongoing remediation measures," in Journal of NepalGeological Society, 2000. Vol. 22, pp. 563-570.

Shrestha, A.B., C.P. Wake, P.A. Mayewski, and J.E. Dibb, 1999. "Maximum Temperature Trends in the Himalaya and its Vicinity: An Analysis Based on Temperature Records from Nepal for the Period 1971 - 94" in Journal of Climate, (12) 2775-2789

Smit, B., I. Burton, R.J.T. Klein and R. Street (1999) 'The science of adaptation: a framework for assessment'. Mitigation and Adaptation Strategies for Global Change. 4. pp. 199213.

Westoby, Mark and Bugman, Mark, Commentary Climate change as a threatening process; Austral Ecology (2006) 31, 549-550

www.unfecc.int/adaptation/items/2973 